\title{
Effects of nitric oxide synthase inhibition on goat oocyte meiotic maturation
}

\author{
Mehdi Heidari Amale, Ahmad Zare Shahne and Salman Nasrollahi \\ Department of Animal Science, College of Agriculture and Natural Resources, University of Tehran, Karaj, Iran
}

\begin{abstract}
Nitric oxide is a biological signalling molecule that plays a crucial role in oocyte maturation of mammalians. It is generated by the nitric oxide synthase enzyme from L-arginine. In this study we assessed the effect of nitric oxide synthase inhibition by $\mathrm{N} \omega$-nitro-L-arginine methyl ester (L-NAME) on meiotic maturation of goat oocytes. So, different concentrations of L-NAME $(0.1$, $1,10 \mathrm{mM}$ ) were added to the maturation medium to evaluate the effect of inhibiting nitric oxide synthase on cumulus expansion and meiotic resumption of goat oocytes. The results showed that none of the concentrations affected cumulus expansion but the formation of the first polar body of the oocytes was suppressed in a dose dependent manner. The highest inhibitory effect was observed with $10 \mathrm{mM} \mathrm{L-NAME}$. Moreover, to confirm the results and to evaluate whether this effect is reversible, $0.1 \mathrm{mM}$ sodium nitroprusside (a nitric oxide donor) was added only to the maturation medium which had the highest concentration of L-NAME $(10 \mathrm{mM})$. The concomitant addition of nitric oxide synthase inhibitor with nitric oxide donor reversed the inhibitory effect of L-NAME on meiotic maturation. These results indicated that the nitric oxide/nitric oxide synthase system is involved in the maturation of goat oocytes and that nitric oxide requirement for nuclear maturation is higher than that for cumulus expansion.
\end{abstract}

Keywords: goat, oocyte maturation, nitric oxide, L-NAME

Abbreviations: CAMP: cyclic adenosine mono-phosphate; COCs: cumulus-oocyte complexes; eNOS: endothelial nitric oxide synthase; IBMX: 3-isobutyl-1-methyl-xanthin; iNOS: inducible nitric oxide synthase; MAPK: mitogen-activated protein kinase; MPF: maturation-promoting factor; mRNA: messenger ribonucleic acid; nNOS: neuronal nitric oxide synthase; L-NAME: N $\omega$-nitro-L-arginine methyl ester; NO: nitric oxide; NOS: nitric oxide synthase; SNP: sodium nitroprusside

Archiv Tierzucht 56 (2013) 25, 255-263

doi: 10.7482/0003-9438-56-025

Corresponding author:

Mehdi Heidari Amale; email: m.heidari@ut.ac.ir

Department of Animal Science, College of Agriculture and Natural Resources, University of Tehran, Karaj, Iran
Received: 25 April 2012

Accepted: 4 July 2012

Online: 8 March 2013

(c) 2013 by the authors; licensee Leibniz Institute for Farm Animal Biology (FBN), Dummerstorf, Germany. This is an Open Access article distributed under the terms and conditions of the Creative Commons Attribution 3.0 License (http://creativecommons.org/licenses/by/3.0/). 


\section{Introduction}

Nitric oxide (NO) is a highly reactive free radical which is involved in inter- and intracellular signalling pathways in various aspects of reproduction such as sexual behaviour, steroidogenesis, follicle survival, ovulation and even embryo implantation in several species (Rosselli et al. 1998, Thaler \& Epel 2003). Nitric oxide is generated from molecular oxygen and L-arginine by nitric oxide synthase (NOS) (Moncada et al. 1991). Nitric oxide synthase exists in three isoforms that have been classified depending on the tissue of origin as well as functional properties (Dixit \& Parvizi 2001). Endothelial NOS (eNOS) and neuronal NOS (nNOS) are calcium and calmodulin dependent and both synthesise small amounts of NO. Inducible NOS (iNOS), the third isoform, is calcium independent and produces a higher amount of NO (Nathan 1992).

All three isoforms of NOS have been identified in the female reproductive system where NO plays an important role in a variety of reproductive functions (Dixit \& Parvizi 2001). In addition to our previous study on sheep oocyte (Heidari Amale et al. 2011), previous literatures have shown that NO is involved in oocyte meiotic maturation of pig (Tao et al. 2005b, Chmelikova et al. 2009), mouse (Bu et al. 2003, 2004), cattle (Matta et al. 2009) and rat (Sela-Abramovich et al. 2008). It is also reported that the NO/NOS system is involved in cumulus cells expansion (Matta et al. 2009, Tao et al. 2005b). It is well known that mammalian ovaries express eNOS, iNOS and nNOS (Van Voorhis et al. 1995, Jablonka-Shariff \& Olson 1998, Klein et al. 1998, Nakamura et al. 2002, Tao et al. 2004). The presence of mRNA for all three isoforms has been recorded in cattle (Tesfaye et al. 2006) and porcine oocytes (Chmelikova et al. 2009). Findings about the effect of the NO/NOS system on the oocyte maturation are different as some researchers have shown that NO inhibits (Jablonka-Shariff \& Olson 1998, Jablonka-Shariff et al. 1999) or others have shown that it stimulates (Sengoku et al. 2001, Bu et al. 2004, Huo et al. 2005, Tao et al. 2005a) the nuclear maturation. However, it seems that there are no reports on the role of the NO/NOS system in maturation of goat oocytes. Nitric oxide has different functional roles such as antioxidant agent, saving cells from oxidative stress (Kanner et al. 1991), however, it can induce cytotoxicity in some cell types (Messmer et al. 1995). The necessity of an appropriate concentration of NO $(0.1 \mathrm{mM})$ for normal maturation of bovine ooctyes were found out by Matta et al. (2002). Viana et al. (2007) showed that a medium dose of NO $(0.1 \mathrm{mM})$ stimulates cytoplasmic maturation of bovine oocytes while its high dose $(10 \mathrm{mM})$ inhibits their nuclear and cytoplasmic maturation.

Thus, based on these established effects of the NO/NOS system on the maturation of mammalian oocytes, the aim of the present study was to investigate the effects of inhibiting NOS on the in vitro maturation of goat oocytes through the addition of different concentrations of a NOS inhibitor, N $\omega$-nitro-L-arginine methyl ester (L-NAME), to the maturation medium. Determination of the effect of different agents, including NO on the in vitro maturation of goat oocytes will improve the quality and quantity of in vitro embryo production. 


\section{Material and methods}

Chemicals and reagents

All chemicals and reagents used in this study were obtained from Sigma-Aldrich (St. Louis, $\mathrm{MI}, \mathrm{USA})$, unless otherwise indicated.

\section{Ovary collection and oocytes selection}

Ovaries were collected from a local slaughterhouse during the non-breeding season (JulyAugust) and were transported to the laboratory in a thermos flask containing sterile saline $\left(0.9 \% \mathrm{NaCl}, 30-35^{\circ} \mathrm{C}\right)$ supplemented with antibiotics $(100 \mathrm{IU} / \mathrm{ml}$ penicillin and $100 \mu \mathrm{g} / \mathrm{ml}$ streptomycin [Gibco/Invitrogen, Life Technologies, Carlsbad, CA, USA]) within 1 - $2 \mathrm{~h}$ following collection. After washing ovaries with freshly prepared sterile saline containing antibiotics, all visible follicles with a diameter of $2-6 \mathrm{~mm}$ were aspirated with a vacuum pump (with pressure of $10 \mathrm{kPa}$ ) equipped with a 20 gauge needle and a $50 \mathrm{ml}$ plastic falcon tube. Follicular fluid containing cumulus-oocyte complexes (COCs) was collected in centrifuge tubes containing TCM-199-HEPES with $5 \%$ FBS (Gibco/Invitrogen), $0.2 \mathrm{mM}$ sodium pyruvate, $100 \mathrm{IU} / \mathrm{ml}$ penicillin, $100 \mu \mathrm{g} / \mathrm{ml}$ streptomycin, $50 \mathrm{IU} / \mathrm{ml}$ heparin and 3-isobutyl-1-methylxanthin (IBMX, 0.5 mM). IBMX inhibits enzyme synthesis that degraded phosphodiesterase CAMP (PD-CAMP), that as a result, maintains meiotic arrest during manipulation of the oocytes (Eppig \& Downs 1984). After deposition, COCs with homogenous cytoplasm and with three or more layers of cumulus cells were selected into plastic dishes $35 \mathrm{~mm}$ in diameter by a narrow-bore pipette for the experiments.

\section{In vitro maturation}

Before culture, selected COCs were collected under stereomicroscope and washed three times in the same medium used for collection without IBMX and two times in the maturation medium used according to the experimental treatments described in the following. Oocytes were matured under mineral oil in $50 \mu \mathrm{l}$ droplets of TCM-199 medium (Gibco/Invitrogen) (ten oocytes per droplet) supplemented with $0.5 \mu \mathrm{g} / \mathrm{ml} \mathrm{FSH}, 5 \mu \mathrm{g} / \mathrm{ml} \mathrm{LH}$ (Sioux Biochemical, Sioux Centre, IA, USA), $1 \mu \mathrm{g} / \mathrm{ml}$ estradiol, $10 \%$ FBS, $100 \mathrm{IU} / \mathrm{ml}$ penicillin and $100 \mu \mathrm{g} / \mathrm{ml}$ streptomycin (as control medium) at $38.5^{\circ} \mathrm{C}$ in $5 \% \mathrm{CO}_{2}$ in air with maximum humidity for 26 hours.

\section{Evaluation of cumulus expansion}

At the end of the culture period, cumulus expansion was assessed using a subjective scoring method described by Tao et al. (2005b) with few modifications. Cumulus expansion was classified into three classes:

- total expansion (expansion of all layers of the cumulus cells),

- partial expansion (expansion of outer layers of the cumulus cells), or

- without expansion (no response observed). 


\section{Evaluation of nuclear maturation}

After evaluation of the cumulus expansion, COCs were mechanically denuded from cumulus cells by repeated pipetting. Denuded oocytes were then mounted on glass slides and fixed with ethanol: acetic acid $(3: 1)$ for $24-48 \mathrm{~h}$ and stained in $2 \%$ acetic orcein. The oocytes were examined under a phase contrast microscope (400x Olympus CKX41, Olympus Corporation, Tokio, Japan) and classified as germinal vesicle, metaphase I, or metaphase II stages (Viana et al. 2007).

\section{Experimental design}

Experiment 1: effects of different L-NAME concentrations on cumulus expansion and nuclear maturation

Increasing concentrations of L-NAME $(0.1,1,10 \mathrm{mM})$ were used to evaluate the cumulus expansion of COCs and nuclear maturation of oocytes during maturation period (26h). Cumulus-oocyte complexes were cultured in four groups to determine whether there was a delay or block in cumulus expansion and/or meiosis progression: 1) without L-NAME (control); 2) with $0.1 \mathrm{mM}$ L-NAME; 3) with $1 \mathrm{mM} \mathrm{L-NAME;} \mathrm{4)} \mathrm{with} 10 \mathrm{mM}$ L-NAME. The most effective concentration $(10 \mathrm{mM})$ was used in the next experiment.

Experiment 2: effect of SNP (a NO donor) on L-NAME-inhibited oocyte maturation

This experiment was aimed to observe whether the inhibitory effect of L-NAME could be reversed by co-administration with a NO donor. So, only in the treatment with the highest L-NAME concentration, $0.1 \mathrm{mM}$ SNP, a NO donor, was added. Then, the COCs were cultured in maturation medium with L-NAME $(10 \mathrm{mM})+$ SNP $(0.1 \mathrm{mM})$ for $26 \mathrm{~h}$.

\section{Statistical analysis}

Statistical analysis was performed using SAS software v. 9.12 (SAS Institute, Cary, NC, USA). All data are presented as mean \pm SEM of four replicates. The results regarding the effect of addition of different concentrations of L-NAME on meiotic maturation and cumulus expansion were evaluated by chi-square test and $P<0.05$ was considered significant.

\section{Results}

\section{Effect of different L-NAME concentrations on cumulus expansion}

After $26 \mathrm{~h}$ of culture, the percentage of COCs without cumulus expansion was similar for all of treatments. Although L-NAME at the highest concentration $(10 \mathrm{mM})$ partially inhibited total expansion, this inhibition wasn't significant (Table 1). 
Table 1

The effect of different L-NAME inhibitor concentrations on cumulus cell expansion of goat oocytes

\begin{tabular}{lcrrr}
\hline Treatments & $\mathrm{n}$ & \multicolumn{3}{c}{ Degree of cumulus expansion, \% } \\
& & \multicolumn{1}{c}{ Total } & Partial & \multicolumn{1}{c}{ Without } \\
\hline Control & 162 & $91.37 \pm 0.28^{\mathrm{a}}$ & $5.55 \pm 0.34^{\mathrm{a} a}$ & $3.08 \pm 0.45^{\mathrm{a}}$ \\
L-NAME & & & & \\
$0.1 \mathrm{mM}$ & 133 & $91 \pm 0.30^{\mathrm{a}}$ & $6 \pm 0.36^{\mathrm{a}}$ & $3 \pm 0.50^{\mathrm{a}}$ \\
$1 \mathrm{mM}$ & 154 & $89 \pm 0.25^{\mathrm{a}}$ & $6.50 \pm 0.32^{\mathrm{a}}$ & $4.50 \pm 0.38^{\mathrm{a}}$ \\
$10 \mathrm{mM}$ & 129 & $86.05 \pm 0.25^{\mathrm{a}}$ & $9.30 \pm 0.30^{\mathrm{a}}$ & $4.65 \pm 0.41^{\mathrm{a}}$ \\
$10 \mathrm{mM}+$ SNP $(0.1 \mathrm{mM})$ & 148 & $89.87 \pm 0.27^{\mathrm{a}}$ & $6.75 \pm 0.33^{\mathrm{a}} \mathrm{a}$ & $3.38 \pm 0.45^{\mathrm{a}}$ \\
\hline
\end{tabular}

Values with different superscripts within the same column are significantly different $(P<0.05)$. Data are presented as mean \pm SEM of four replicates.

\section{Effects of different L-NAME Concentrations on nuclear maturation}

The addition of different concentrations of L-NAME to the maturation medium inhibited the formation of the first polar body (as complete nuclear maturation) in a dose-dependent manner (Table 2) and the percentage of metaphase II reached to the minimum level in the concentration of $10 \mathrm{mM} \mathrm{L-NAME}(32.23 \pm 0.19 \%)$. Also, L-NAME at the concentration of $10 \mathrm{mM}$ significantly increased the percentage of oocytes which were remained at germinal vesicle stage, while other concentrations of L-NAME exhibited no inhibitory effect on germinal vesicle compared with the control. In experiment 2, SNP $(0.1 \mathrm{mM})$ that could effectively reverse the inhibitory effect of L-NAME on cumulus expansion also promoted meiotic resumption and reversed the inhibitory effect of L-NAME $(10 \mathrm{mM})$ on germinal vesicle.

Table 2

Effect of different L-NAME inhibitor concentrations on nuclear maturation of goat oocytes

\begin{tabular}{lcccc}
\hline Treatments & $\mathrm{n}$ & \multicolumn{3}{c}{ Stage of nuclear maturation } \\
& & Germinal vesicle, \% & Metaphase I, \% & Metaphase II, \% \\
\hline Control & 149 & $2.02 \pm 0.58^{\mathrm{b}}$ & $20.80 \pm 0.2^{\mathrm{c}}$ & $77.18 \pm 0.19^{\mathrm{a}}$ \\
L-NAME & & & & \\
$0.1 \mathrm{mM}$ & 120 & $1.67 \pm 0.71^{\mathrm{b}}$ & $32.50 \pm 0.19^{\mathrm{b}}$ & $65.83 \pm 0.19^{\mathrm{b}}$ \\
$1 \mathrm{mM}$ & 146 & $2.75 \pm 0.50^{\mathrm{b}}$ & $53.42 \pm 0.16^{\mathrm{a}}$ & $43.83 \pm 0.16^{\mathrm{c}}$ \\
$10 \mathrm{mM}$ & 121 & $6.61 \pm 0.36^{\mathrm{a}}$ & $61.16 \pm 0.18^{\mathrm{a}}$ & $32.23 \pm 0.19^{\mathrm{d}}$ \\
$10 \mathrm{mM}+\mathrm{SNP}(0.1 \mathrm{mM})$ & 142 & $2.11 \pm 0.58^{\mathrm{b}}$ & $21.84 \pm 0.20^{\mathrm{c}}$ & $76.05 \pm 0.19^{\mathrm{a}}$ \\
\hline
\end{tabular}

Values with different superscripts within the same column are significantly different $(P<0.05)$. Data are presented as mean $\pm S E M$ of four replicates. 


\section{Discussion}

This study demonstrated that in vitro maturation of goat oocytes was clearly affected by the different concentrations of L-NAME, a NOS inhibitor, $(0.1,1,10 \mathrm{mM})$. The meiotic progression was suppressed by all concentrations in a dose-dependent manner. Moreover, the concomitant addition of SNP, a NO donor, reversed the inhibitory effects of L-NAME on meiotic maturation. This is the first report on the effect of the NO/NOS system in maturation of goat oocytes. Similar results have been obtained in sheep (Heidari Amale et al. 2011), cattle (Schwarz et al. 2008, Matta et al. 2009), mice (Bu et al. 2003), swine (Tao et al. 2005a, Chmelikova et al. 2010) and rat (Jablonka-Shariff et al. 1999).

Nitric oxide is a free radical gas with critical physiological functions (Moncada et al. 1991). There are many mechanisms such as activating soluble guanylate cyclase $(\mathrm{s} G C)$ and the synthesis of CGMP, inhibition of adenylyl cyclase (AC), alteration of phosphodiesterase (PDE), activation of calcium-dependent potassium channels and activating $G_{i}$ through which NO may affect mammalian cells (Tranguch et al. 2003, Bu et al. 2004), but the exact mechanism of the influence of the NO/NOS system on oocyte maturation has not been fully clarified to date. N $\omega$-nitro-L-arginine methyl ester is a non-selective inhibitor of NOS that can reduce the production of NO by inhibiting the expression of both eNOS and iNOS. It is reported that iNOS-derived NO is necessary for cumulus expansion and meiotic maturation by mediating the function of the surrounding cumulus cells, and eNOS-derived NO is also involved in porcine meiotic maturation (Tao et al. 2005b). Ovarian nitric oxide synthesis is required for maximal ovulation, and a lack of NO during the periovulatory period results in severe defects in oocyte maturation (Jablonka-Shariff et al. 1999).

Our previous study on sheep oocytes (Heidari Amale et al. 2011) represented that a concentration of $10 \mathrm{mM}$ L-NAME could affect the cumulus expansion. It may indicate that sheep oocytes are more sensitive than goat oocytes to NO deficiency in maturation medium.

Regarding the assessment of the nuclear maturation in the present study, L-NAME inhibited nuclear maturation in a dose-dependent manner, and the biggest inhibition rate on nuclear maturation was obtained with $10 \mathrm{mM}$ L-NAME. Ion the other hand, low and intermediate levels of L-NAME (0.1 and $1 \mathrm{mM}$ ) could suppress the progression of meiotic maturation, while these concentrations hadn't any significant effect on the cumulus expansion. It shows that the required NO concentration for nuclear maturation is higher than that of cumulus expansion. These findings agree with previous studies which reported that NOS inhibition by L-NAME reduced the meiosis progression of oocytes in metaphase II stage (Jablonka-Shariff \& Olson 2000, Sengoku et al. 2001, Tao et al. 2004, Schwarz et al. 2008, Heidari Amale et al. 2011). In addition to metaphase I- metaphase II transition, the inhibition of NOS with L-NAME (at $10 \mathrm{mM}$ ) enhanced the percentage of oocytes that remained in germinal vesicle stage after the maturation period. Our result was similar with those from sheep (Heidari Amale et al. 2011), mouse (Bu et al. 2003) and porcine (Tao et al. 2005a, Chmelikova et al. 2010) oocytes. However, other literatures (Bu et al. 2004, Schwarz et al. 2008) have reported that L-NAME hasn't any effect on the germinal vesicle breakdown.

In mammals, meiosis arrest and resumption are modulated by numerous messengers including cyclic adenosine mono-phosphate (cAMP), cAMP-dependent protein kinase (PKA) and calcium ions (Van den Hurk \& Zhao 2005, Tosti 2006). It is well established that intraoocyte 
CAMP levels play an important role in the maintenance of the meiotic arrest at the diplotene (germinal vesicle) stage in mouse oocyte (Mehlmann 2005). But results obtained in cattle (Sirard et al. 1992) or sheep (Moor \& Heslop 1981) indicated that CAMP accumulation in the oocyte may not be the principal physiological way to maintain meiotic arrest. Therefore, we suggested other mechanisms for the involvement of NOS inhibition on the meiotic arrest of goat oocytes. It is well known that meiotic maturation is regulated by maturation-promoting factor (MPF) and mitogen-activated protein kinase (MAPK) (Lu et al. 2002). It seems that the deficiency in NO production by using NOS inhibition might have affected the meiotic maturation via one of these mechanisms.

Independently of differences between animal species, MPF and MAPK activation are both important in oocyte maturation. Interference in any of these processes will inhibit MPF and MAPK activation, preventing resumption of meiosis and arresting the oocyte at germinal vesicle stage.

At the protein level, the mitogen-activated protein was present in constant amounts throughout the first meiotic division in mice. It has been shown that MAPK activation occurred after the germinal vesicle breakdown, indicating that MAPK is not required for the germinal vesicle breakdown but is involved in regulating post-germinal vesicle breakdown events (Lu et al. 2002). Unlike MAPK, MPF activity increases just before germinal vesicle breakdown and during metaphase I. It is reported that MPF plays a key role in the maintenance of germinal vesicle arrest in mammalian oocytes (Tripathi et al. 2010). Lander et al. (1996) suggest that NO and reactive oxygen intermediates activate the MAPK family in human cells through upstream activation. Huo et al. (2005) also reported that the phosphorylation of MAPK was inhibited by aminoguanidine (AG, a specific inhibitor for $\mathrm{iNOS}$ ) in mouse oocyte. Oocyte maturation is accompanied by important structural changes, such as the reorganisation of organelles upon germinal vesicle breakdown (Albertini et al. 1987), formation of the meiotic spindle (Albertini 1992) and chromosome segregation (Longo \& Chen 1985). Gordo et al. (2001) demonstrated that in bovine oocytes MAPK activity is required for spindle organisation. Lu et al. (2002) also reported that active MAPK is required for normal meiotic spindle formation and chromosome condensation and the inhibition of MAPK activation resulted in compromised microtubule polymerisation, no spindle formation and a loosely condensed chromosome. These data suggest that L-NAME may cause the inhibition of the phosphorylation of MAPK and MPF activity and subsequently the inhibition of metaphase I- metaphase II transition and is stopped at germinal vesicle stage. However, more experiments are necessary to advance this hypothesis in goat oocytes.

In conclusion, our results demonstrated that the NO/NOS system is involved in the maturation of goat oocytes and a lack of NO during the maturation results in sever defects in oocytes maturation. Although NO is needed for nuclear maturation and cumulus expansion of goat oocytes, NO requirement for meiotic maturation is higher than that for cumulus expansion. Understanding the control mechanisms of NO in oocyte meiotic maturation may lead to improved techniques for oocyte maturation and embryo production. 


\section{References}

Albertini DF (1992) Regulation of Meiotic Maturation in the Mammalian Oocyte: Interplay Between Exogenous Cues and the Microtubule Cytoskeleton. BioEssays 14, 97-103

Albertini DF, Overstrom EW, Ebert KM (1987) Changes in the Organization of the Actin Cytoskeleton during Preimplantation Development of the Pig Embryo. Biol Reprod 37, 441-451

Bu S, Xia G, Tao Y, Lei L, Zhou B (2003) Dual effects of nitric oxide on meiotic maturation of mouse cumulus cell-enclosed oocytes in vitro. Mol Cell Endocrinol 207, 21-30

Bu S, Xie H, Tao Y, Wang J, Xia G (2004) Nitric oxide influences the maturation of cumulus cell-enclosed mouse oocytes cultured in spontaneous maturation medium and hypoxanthine-supplemented medium through different signaling pathways. Mol Cell Endocrinol 223, 85-93

Chmelikova E, Sedmikova M, Petr J, Kott T, Lanska V, Tumova L, Tichovska H, Jeseta M (2009) Expression and localization of nitric oxide synthase isoforms during procine oocyte growth and acquisition of meiotic competence. Czech J Anim Sci 54, 137-149

Chmelikova E, Jeseta M, Sedmikova M, Petr J, Tumova L, Kott T, Lipovova P, Jilek F (2010) Nitric oxide synthase isoforms and the effect of their inhibition on meiotic maturation of porcine oocytes. Zygote 18, 235-244

Dixit VD, Parvizi N (2001) Nitric oxide and the control of reproduction. Anim Reprod Sci 65, 1-16

Eppig JJ, Downs SM (1984) Chemical Signals that Regulate Mammalian Oocyte Maturation. Biol Reprod 30, 1-11

Gordo AC, He CL, Smith S, Fissore RA (2001) Mitogen Activated Protein Kinase Plays a Significant Role in Metaphase II Arrest, Spindle Morphology, and Maintenance of Maturation Promoting Factor Activity in Bovine Oocytes. Mol Reprod Dev 59, 106-114

Heidari Amale M, Zare Shahne A, Abavisani A, Nasrollahi S (2011) Effects of inhibiting nitric oxide synthase on cumulus expansion and nuclear maturation of sheep oocytes. Czech J Anim Sci 56, 284-291

Huo LJ, Liang CG, Yu LZ, Zhong ZS, Yang ZM, Fan HY, Chen DY, Sun QY (2005) Inducible nitric oxide synthasederived nitric oxide regulates germinal vesicle breakdown and first polar body emission in the mouse oocyte. Reproduction 129, 403-409

Jablonka-Shariff A, Basuray R, Olson LM (1999) Inhibitors of Nitric Oxide Synthase Influence Oocyte Maturation in Rats. J Soc Gynecol Investig 6, 95-101

Jablonka-Shariff A, Olson LM (1998) The Role of Nitric Oxide in Oocyte Meiotic Maturation and Ovulation: Meiotic Abnormalities of Endothelial Nitric Oxide Synthase Knock-Out Mouse Oocytes. Endocrinology 139, 2944-2954

Jablonka-Shariff A, Olson LM (2000) Nitric Oxide Is Essential for Optimal Meiotic Maturation of Murine Cumulus-Oocyte Complexes In Vitro. Mol Reprod Dev 55, 412-421

Kanner J, Harel S, Rina G (1991) Nitric oxide as an antioxidant. Arch Biochem Biophys 289, 130-136

Klein SL, Carnovale D, Burnett AL, Wallach EE, Zacur HA, Crone JK, Dawson VL, Nelson RJ, Dawson TM (1998) Impaired ovulation in mice with targeted deletion of the neuronal isoform of nitric oxide synthase. Mol Med 4, 658-664

Lander HM, Jacovina AT, Davis RJ, Tauras JM (1996) Differential Activation of Mitogen-activated Protein Kinases by Nitric Oxide-related Species. J Biol Chem 271, 19705-19709

Longo FJ, Chen DY (1985) Development of Cortical Polarity in Mouse Eggs: Involvement of the Meiotic Apparatus. Dev Biol 107, 382-394

Lu Q, Dunn RL, Angeles R, Smith GD (2002) Regulation of Spindle Formation by Active Mitogen-Activated Protein Kinase and Protein Phosphatase 2A During Mouse Oocyte Meiosis. Biol Reprod 66, 29-37

Matta SG, Bussiere MCC, Viana KS, Quirino CR (2002) [Effect of different concentrations of the inhibitor of nitric oxide synthesis on the in vitro nuclear maturation of bovine oocytes]. Revista Brasileira de Reproducao Animal 26, 149-151 [in Portugese]

Matta SGC, Caldas-Bussiere MC, Viana KS, Faes MR, Paes de Carvalho CS, Dias BL, Quirino CR (2009) Effect of inhibition of synthesis of inducible nitric oxide synthase-derived nitric oxide by aminoguanidine on the in vitro maturation of oocyte-cumulus complexes of cattle. Anim Reprod Sci 111, 189-201 
Mehlmann LM (2005) Stops and starts in mammalian oocytes: recent advances in understanding the regulation of meiotic arrest and oocyte maturation. Reproduction 130, 791-799

Messmer UK, Lapetina EG, Brüne B (1995) Nitric oxide-induced apoptosis in RAW 264.7 macrophages is antagonized by protein kinase $C$ - and protein kinase A-activating compounds. Mol Pharmacol 47, 757-765

Moncada S, Palmer RMJ, Higgs EA (1991) Nitric Oxide: Physiology, Pathophysiology, and Pharmacology. Pharmacol Rev 43, 109-142

Moor RM, Heslop JP (1981) Cyclic AMP in Mammalian Follicle Cells and Oocytes During Maturation. J Exp Zool A Ecol Genet Physiol 216, 205-209

Nakamura Y, Yamagata Y, Sugino N, Takayama H, Kato H (2002) Nitric Oxide Inhibits Oocyte Meiotic Maturation. Biol Reprod 67, 1588-1592

Nathan C (1992) Nitric oxide as a secretory product of mammalian cells. The FASEB Journal 6, 3051-3064

Rosselli M, Keller RJ, Dubey RK (1998) Role of nitric oxide in the biology, physiology and pathophysiology of reproduction. Hum Reprod Update 4, 3-24

Schwarz KRL, Pires PRL, de Bem THC, Adona PR, Leal CLV (2010) Consequences of Nitric Oxide Synthase Inhibition During Bovine Oocyte Maturation on Meiosis and Embryo Development. Reprod Domest Anim $45,75-80$

Sela-Abramovich S, Galiani D, Nevo N, Dekel N (2008) Inhibition of Rat Oocyte Maturation and Ovulation by Nitric Oxide: Mechanism of Action. Biol Reprod 78, 1111-1118

Sengoku K, Takuma N, Horikawa M, Tsuchiya K, Komori H, Sharifa D, Tamate K, Ishikawa M (2001) Requirement of Nitric Oxide for Murine Oocyte Maturation, Embryo Development, and Trophoblast Outgrowth In Vitro. Mol Reprod Dev 58, 262-268

Sirard MA, Coenen K, Bilodeau S (1992) Effect of fresh or cultured follicular fractions on meiotic resumption in bovine oocytes. Theriogenology 37, 39-57

Tao JY, Fu Z, Zhang ML, Xia G, Lei L, Wu ZL (2005a) Nitric oxide influences the meiotic maturation of porcine oocytes cultured in hypoxanthine-supplemented medium. J Anim Physiol Anim Nutr (Berl) 89, 38-44

Tao Y, Fu Z, Zhang M, Xia G, Yang J, Xie H (2004) Immunohistochemical localization of inducible and endothelial nitric oxide synthase in porcine ovaries and effects of $\mathrm{NO}$ on antrum formation and oocyte meiotic maturation. Mol Cell Endocrinol 222, 93-103

Tao Y, Xie H, Hong H, Chen X, Jang J, Xia G (2005b) Effects of nitric oxide synthase inhibitors on porcine oocyte meiotic maturation. Zygote 13, 1-9

Tesfaye D, Kadanga A, Rings F, Bauch K, Jennen D, Nganvongpanit K, Hölker M, Tholen E, Ponsuksili S, Wimmers K, Montag M, Gilles M, Kirfel G, Herzog V, Schellander K (2006) The Effect of Nitric Oxide Inhibition and Temporal Expression Patterns of the mRNA and Protein Products of Nitric Oxide Synthase Genes During In Vitro Development of Bovine Pre-implantation Embryos. Reprod Domest Anim 41, 501-509

Thaler CD, Epel D (2003) Nitric Oxide in Oocyte Maturation, Ovulation, Fertilization, Cleavage and Implantation: A little dab'll do ya. Curr Pharm Des 9, 399-409

Tosti E (2006) Calcium ion currents mediating oocyte maturation events. Reprod Biol Endocrinol 4, 26

Tranguch S, Steuerwald N, Huet-Hudson YM (2003) Nitric Oxide Synthase Production and Nitric Oxide Regulation of Preimplantation Embryo Development. Biol Reprod 68, 1538-1544

Tripathi A, Prem Kumar KV, Chaube SK (2010) Meiotic Cell Cycle Arrest in Mammalian Oocytes. J Cell Physiol 223, 592-600

Van Voorhis BJ, Moore K, Strijbos PJ, Nelson S, Baylis SA, Grzybicki D, Weiner CP (1995) Expression and localization of inducible and endothelial nitric oxide synthase in the rat ovary. Effects of gonadotropin stimulation in vivo. J Clin Invest 96, 2719-2726

Van den Hurk R, Zhao J (2005) Formation of mammalian oocytes and their growth, differentiation and maturation within ovarian follicles. Theriogenology 63, 1717-1751

Viana KS, Caldas-Bussiere MC, Matta SGC, Faes MR, Paes de Carvalho CS, Quirino CR (2007) Effect of sodium nitroprusside, a nitric oxide donor, on the in vitro maturation of bovine oocytes. Anim Reprod Sci 102, 217-227. 